\title{
Editorial Report
}

\author{
László Solymosi ${ }^{1}$
}

Published online: 11 August 2017

(c) Springer-Verlag GmbH Germany 2017

Traditionally, the most recent Impact Factor is published every year in the month of June. This year, we were again awaiting the annual announcement of the Impact Factors with particular interest, to see whether our journal's positive trend had continued. Unfortunately, for the first time the Impact Factor did not increase in comparison to the previous year. The current Impact Factor of Clinical Neuroradiology is 2.618 .

The good news is that our journal is still ranked second in the field of neuroradiology, since all other journals in the field with the exception of AJNR also showed a decrease in their Impact Factor in comparison to the previous year. (Fig. 1)

These figures seem to point to a general trend. Nonetheless, we cannot content ourselves with this explanation, but must make every effort to build on our previous success. We hope that you regularly read the papers published in Clinical Neuroradiology and find them of sufficient quality to warrant frequent citation. Needless to say, we expect to continue to receive outstanding submissions for publication.

The number of submitted papers remains stable, with around $20 \%$ of submissions coming from Germany and $10 \%$ from the USA. Numerous papers are submitted from Asia. Unlike many other journals, we do not have to send out masses of e-mails asking for submissions. With a rejection rate of close to $80 \%$, we ensure that only excellent papers are accepted for our journal.

László Solymosi

solymosi_1@ukw.de

1 Dept. of Neuroradiology, University Hospital of Würzburg, Würzburg, Germany
In contrast, there is still room for improvement in the peer-review process; the response times and adherence to deadlines need to be, and will be, improved.

The Editorial Board is working hard to keep Clinical Neuroradiology right where it belongs, among the leading journals in the field of neuroradiology, and we hope we can count on our valued readers and reviewers to continue to support us in the future.

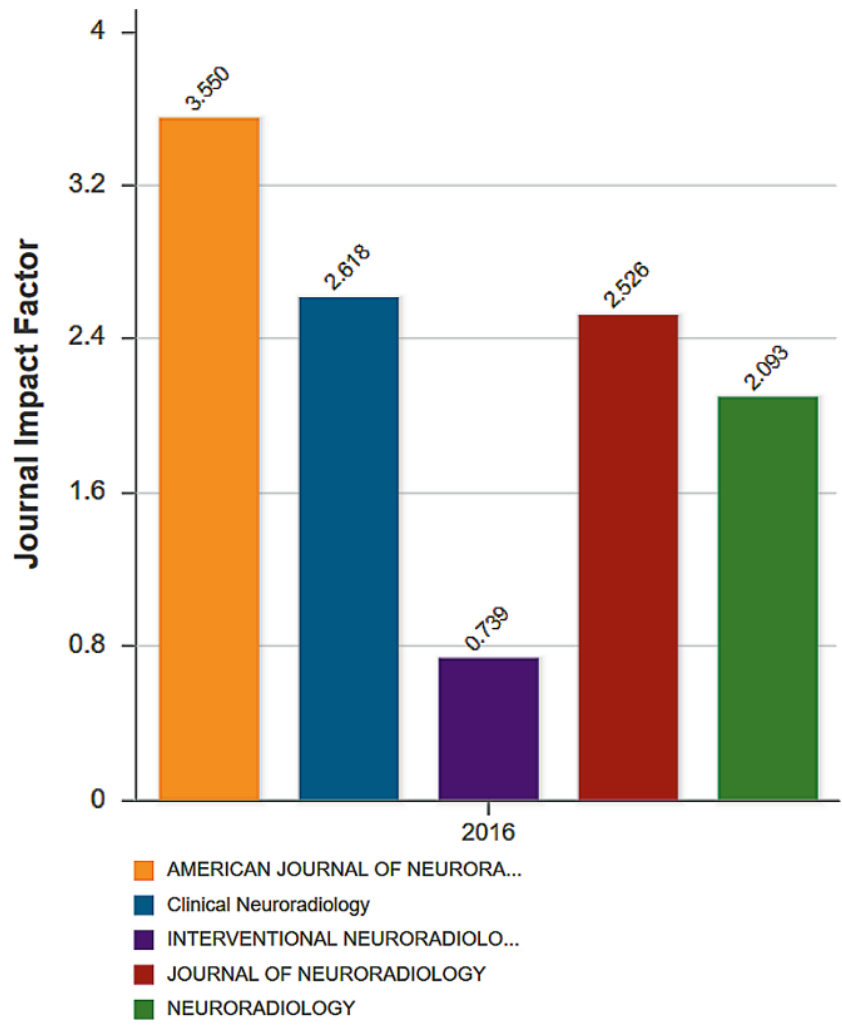

Fig. 12016 Impact Factors of neuroradiology journals in comparison. (Source: InCites ${ }^{\mathrm{TM}}$ Journal Citation Reports ${ }^{\circledR}$, Thomson Reuters ${ }^{\mathrm{TM}}$ ) 